\title{
Validity of a simple footprint assessment board for diagnosing the severity of flatfoot: a prospective cohort study
}

Seikai Toyooka', Naoya Shimazaki², Youichi Yasui', Shuji Ando³, Yasuaki Saho', Takumi Nakagawa', Hirotaka Kawano ${ }^{1}$ and Wataru Miyamoto ${ }^{1 *}$

\begin{abstract}
Background: A simple, non-quantitative, and cost-effective diagnostic tool would enable the diagnosis of flatfoot without need for specialized training. A simple footprint assessment board that investigates which toe the cord passes through from the centre point of the heel to the most lateral point of the medial contour of the footprint has been developed to assess flatfoot. The purpose of this study was to verify the validity of a simple footprint assessment board for flatfoot.
\end{abstract}

Methods: Thirty-five consecutive patients with foot pain, foot injury, or any associated symptoms who underwent computed tomography (CT) were analysed prospectively. At the time of the $\mathrm{CT}$ scan, a footprint analysis using a simple footprint assessment board was performed. The navicular index, tibiocalcaneal angle, and calcaneal inclination angle were evaluated by $C T$ to assess flat feet. These three criteria were compared to those evaluated with the simple footprint assessment board by regression analysis. In addition, the same analysis was conducted separately for young, middle-aged, and older patients in order to investigate each age group.

Results: The navicular index and tibiocalcaneal angle generally decreased as the score of the simple footprint assessment board increased. Calcaneal inclination angle generally increased as the score of the simple footprint assessment board increased. As the scores of the simple footprint assessment board decreased by approaching the great toe, the navicular index and tibiocalcaneal angle were higher and calcaneal inclination angle was lower, which is indicative of a higher likelihood of flatfoot. The scores derived from the simple footprint assessment board was correlated with these three criteria measured by $C T$, not only when the result of simple footprint assessment board was set as a non-continuous variable but also when the result was set as a continuous variable. The results of the age-stratified survey were similar for all groups.

Conclusions: The findings of this study suggest that a simple footprint assessment board can be potentially useful to detect flatfoot.

Trial registration: Retrospectively registered.

Keywords: Flatfoot, Footprint assessment board, Arch height, Navicular index

\footnotetext{
* Correspondence: miyamoto@med.teikyo-u.ac.jp

'Department of Orthopaedic Surgery, Teikyo University School of Medicine,

Tokyo, Japan

Full list of author information is available at the end of the article
}

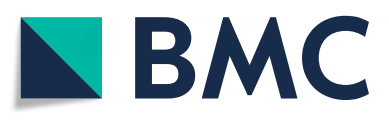

(c) The Author(s). 2021 Open Access This article is licensed under a Creative Commons Attribution 4.0 International License, which permits use, sharing, adaptation, distribution and reproduction in any medium or format, as long as you give appropriate credit to the original author(s) and the source, provide a link to the Creative Commons licence, and indicate if changes were made. The images or other third party material in this article are included in the article's Creative Commons licence, unless indicated otherwise in a credit line to the material. If material is not included in the article's Creative Commons licence and your intended use is not permitted by statutory regulation or exceeds the permitted use, you will need to obtain permission directly from the copyright holder. To view a copy of this licence, visit http://creativecommons.org/licenses/by/4.0/. The Creative Commons Public Domain Dedication waiver (http://creativecommons.org/publicdomain/zero/1.0/) applies to the data made available in this article, unless otherwise stated in a credit line to the data. 


\section{Background}

Flatfoot deformity is a medical condition characterized by a flattened arch on the medial border of the plantar foot wherein the entire sole of the foot comes into nearcomplete contact with the ground [1]. The prevalence of flatfoot has been reported as approximately $26.5 \%[2,3]$. A compromised function of the foot arc may increase the risk of overuse injury and continuous pain, the former of which can cause advanced hindfoot deformity such as osteoarthritis of the subtalar and Chopart joints in patients with flatfoot $[4,5]$. In addition, flatfoot is also associated with osteoarthritis of the knee and hip dysplasia, and early diagnosis and treatment are crucial for the prevention of disease progression $[6,7]$.

Several clinical diagnostic approaches have been adopted to identify flatfoot, including the assessment of clinical symptoms $[8,9]$, radiographic imaging $[8,10]$, and footprint analysis [11-14]. The most common diagnostic measure for flatfoot is the assessment of clinical symptoms and physical findings; however, the processes of evaluation can be subjective and may require clinical experience [15]. In the case of radiographic diagnosis, a set of angular parameters is used to assess the degree of deformity from standard dorsoplantar and lateral radiographs of the weight-bearing feet [1]. There are several disadvantages associated with radiological assessment, including the difficulty in determining these angles, discrepancies in imaging quality due to varying competencies of radiologic technicians, inter- or intraobserver error, and exposure to radiation $[8,16-18]$.

On the other hand, footprint analysis is a simple, quick, cost-effective, and readily available method and has been recommended as a screening tool for flatfoot [11-14]. Although previous studies have developed various footprint analyses for the assessment of the arch that have been considered reliable by many researchers, these procedures require measurements of area, angle, and distance using an image of the footprint, in addition to occasional calculations to determine the ratio of the distances $[11,13,14,16]$. A simplified and non-quantitative diagnostic tool would be greatly beneficial for medical workers to diagnose flatfoot without need for specialized training. A medical equipment manufacturer has recently developed a simple footprint assessment board that investigates which toe the cord passes through from the centre point of the heel to the most lateral point of the medial contour of the footprint with a thermochromic surface to describe the footprint and assess flatfoot; however, there has been no verification on the diagnostic accuracy obtained by this board. The purpose of this study was to verify the validity of a simple footprint assessment board for flatfoot. The hypothesis was that there is a correlation between the results of the simple assessment board and the radiological assessment for the diagnosis of flatfoot. If the hypothesis can be proven, a simple tool can be used for an accurate assessment of flatfoot without radiation exposure, high cost, and timeconsuming measurements.

\section{Methods \\ Patients and design}

Data for consecutive patients with foot pain, foot injury, or any associated symptoms who underwent computed tomography (CT) between January 2019 and June 2020 at a single institution were analysed prospectively. At the time of the CT scan, a footprint analysis using a simple footprint assessment board (Arch Check Board, NIPPON SIGMAX, Tokyo, Japan) was also performed. The results for the arch height evaluated by CT was compared to those evaluated by the simple footprint assessment board. The study protocol was approved by the institutional review board of the author's institution and all patients provided informed consent. For patients under 18 years of age, informed consent was granted by their parents or legally authorized representatives. The exclusion criteria were as follows: history of lower extremity surgery, patients with symptoms that prevent them from loading their lower extremities, patients with a capillary refill time of more than $2 \mathrm{~s}$ who were not expected to produce a clear thermal impression on the thermochromic surface of the simple footprint assessment board.

\section{Measurements}

For each person included in this study, anthropometric variables (age, gender, and body mass index) were examined, in addition to the reason for undergoing CT. In this study, the validity to assess arch height was evaluated with a simple footprint assessment board. Patients placed their feet on a thermochromic sheet that was placed on the top of this board to check for discoloration. The discoloration produced an accurate footprint on the board. A cord was attached to the board which was fixed to the centre point of the heel with a magnet at its other end. To measure the arch height, the cord was set up to contact the most lateral point of the medial contour of the footprint and fixed to a magnetic strip located distally to the toes (Fig. 1). The evaluation was performed by determining which toe the cord passed through and scored as follows: 1, the cord passed through the footprint of the great toe; 2 , through the second toe; 3 , through the third toe; 4 , through the fourth toe; 5 , through the fifth toe. When the cord passed through the medial region of the great toe, the evaluation was defined as 0.5 , and when the cord passed between toes, a score of 0.5 was added to the score of lesser toes (i.e., 1.5 when the cord passed between the great toe and second toe, and 2.5 when passed between 


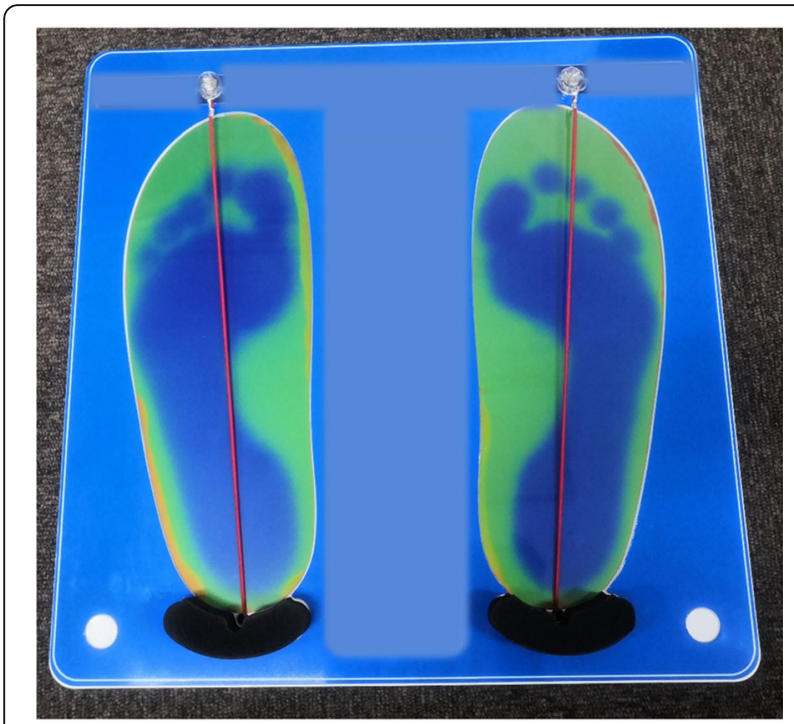

Fig. 1 A photograph of the simple footprint assessment board with thermochromic discoloration of footprint

second and third toes) (Fig. 2). This measurement was performed by a skilled radiologic technician who was blinded to the patient's background. A greater score indicated a greater arch height.

CT (Toshiba Aquilion, Canon Medical Systems Cooperation, Otawara, Japan) was performed with the standard bone CT protocol with $0.5-\mathrm{mm}$ axial sections in three planes, with a tube voltage of $120 \mathrm{kV}$. After creating a 3D computed tomography image, three criteria were evaluated. First, the navicular index was evaluated according to a method described by Roth et al. [19]. They introduced the navicular index as a new measure to distinguish between flatfoot and normal foot. A greater navicular index suggested a higher likelihood of a flatfoot. A line connecting the lowest point of the first metatarsal head to the lowest point of the calcaneus was created with the 3D CT image. The distance between the lowest point of the first metatarsal head and the lowest point of the calcaneus was defined as "the length of the longitudinal arch." A plane was subsequently created to passed through the lowest point of the first metatarsal head, the lowest part of the fifth metatarsal head, and the lowest part of the calcaneus. The distance of the perpendicular line from the lowest point of the navicular bone to this plane was measured and defined as "the navicular height" (Fig. 3A). The navicular index which was calculated by dividing the length of the longitudinal arch with navicular height was investigated. A higher navicular index indicated a lower arch height. Second, the tibiocalcaneal angle was evaluated according to a method described by Lee et al. [20]. This angle was defined as the angle between the axis of distal tibial shaft and the medial calcaneal contour. The axis of the distal

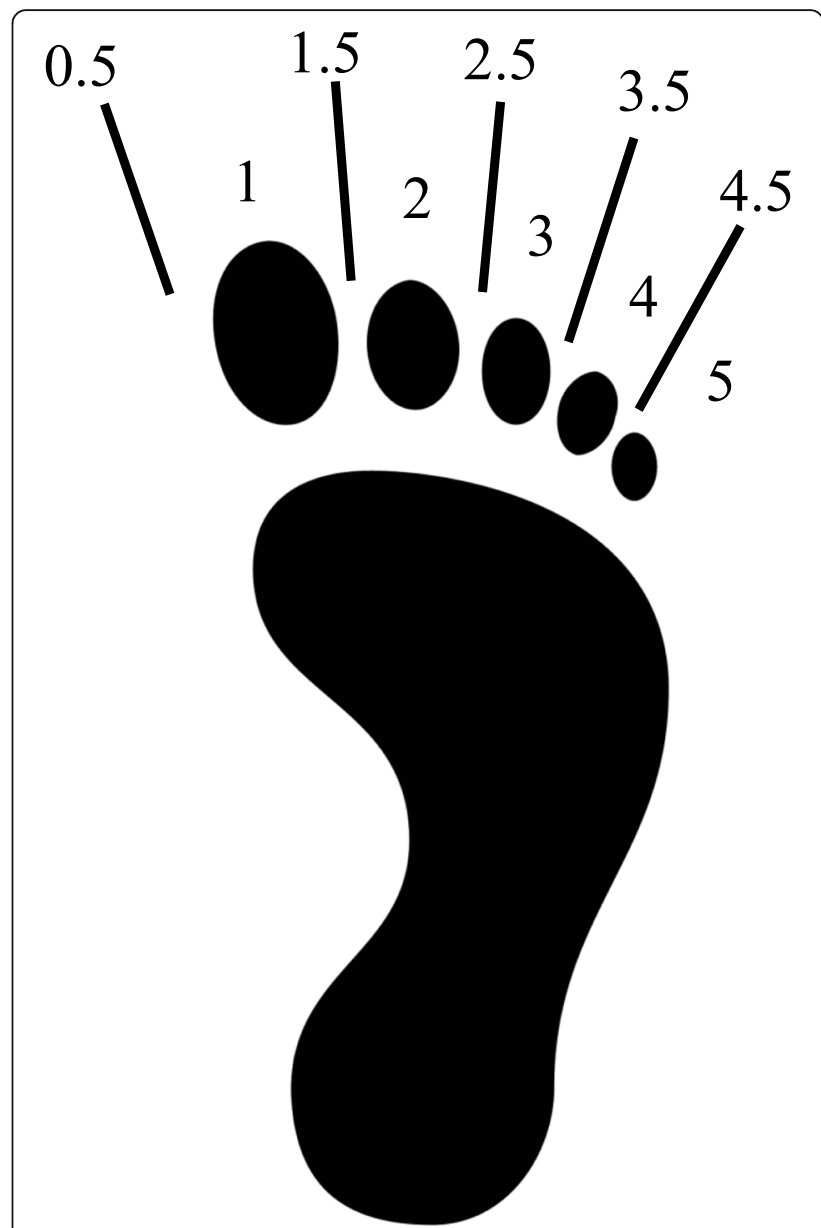

Fig. 2 Scoring for the simple footprint assessment board

tibial shaft was first drawn through the centre of the tibial shaft, which was defined by the midpoint of two pairs of points on the distal tibial cortex in coronal CT image through the maximum width of the tibial shaft. Then, a line of the medial calcaneal contour was drawn along the medial calcaneal wall in coronal CT image through the posterior tibial cortex. The resulting angle between these 2 lines was defined as the tibiocalcaneal angle (Fig. $3 \mathrm{~B})$. Third, the calcaneal inclination angle was evaluated according to a method described by de Cesar Netto et al. [21]. This angle was defined as the junction of 1) the plantar line and 2) a line connecting the most inferior point and edge of the calcaneal tuberosity and anterior process of the calcaneus in sagittal CT image, respectively (Fig. 3C). The latter two are both part of the assessment used to evaluate flat feet. Since these two radiographic angles are well correlated with weightbearing and non-weight-bearing conditions [21, 22], the measurement can be carried out without concern for load conditions. SYNAPSE VINCENT Ver. 3.3 (FUJIFILM Cooperation, Tokyo, Japan) was used for these measurements as an image analysis software. CT images 

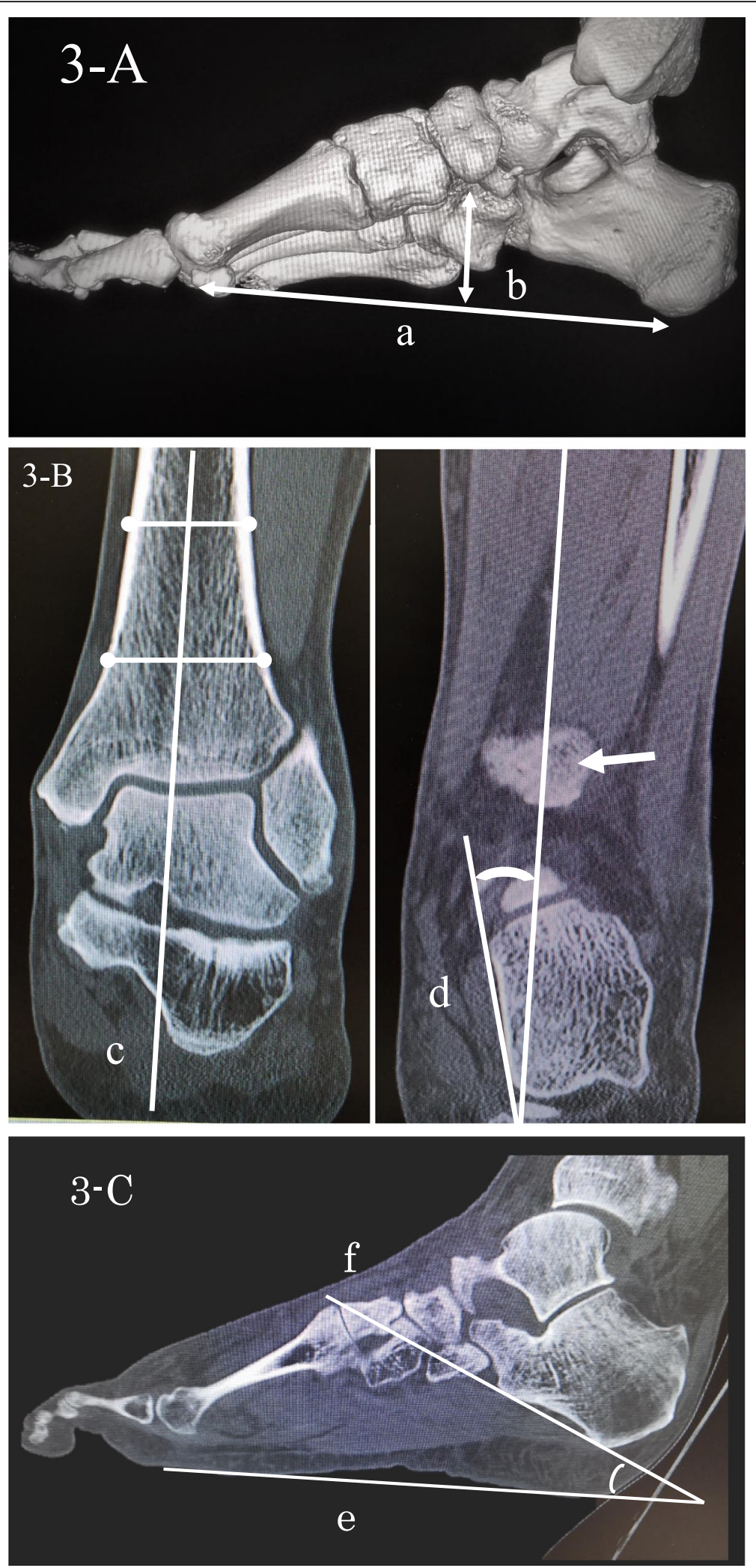

Fig. 3 (See legend on next page.) 
(See figure on previous page.)

Fig. 3 The methodology of measuring the longitudinal arch length and navicular height with 3DCT imaging (A), tibiocalcaneal angle with coronal CT image (B), and calcaneal inclination angle with sagittal CT image (C). A. a: The length of the longitudinal arch. b: The navicular height. B. c: The axis of the distal tibia. d: A line of the medial calcaneal contour. White arrow: The posterior tibial cortex. C. e: The plantar line. f: The most inferior point of the calcaneal tuberosity and the inferior edge of the anterior process of the calcaneus

were evaluated independently by orthopaedic surgeons with 15 years of clinical experience and were blinded to the clinical and patient data.

The relationship between the results of evaluation by the simple footprint assessment board and the navicular index, tibiocalcaneal angle, and calcaneal inclination angle by $\mathrm{CT}$ was evaluated. In order to examine the results of the survey that were stratified by age, the same survey was conducted for the young group ( $\leq 35$ years), the middle-aged group (36- 55 years), and the older group ( $>56$ years).

Intrarater reliability in the measurement of the simple footprint assessment board was assessed using the intraclass correlation coefficient (ICC). Measurements were repeated two times on every foot in this study. In order to evaluate the reliability of radiographic variables, intraobserver and interobserver reliabilities were assessed using ICC. Measurements of the navicular index, tibiocalcaneal angle, and calcaneal inclination angle by $\mathrm{CT}$ were repeated two times on every patient for intraobserver reliability. To evaluate for interobserver reliability, another orthopaedic surgeon conducted the measurements and comparisons for all patients.

\section{Statistical analysis}

When examining the relationship between the result of the simple footprint assessment board and the navicular index, tibiocalcaneal angle, and calcaneal inclination angle, the current study was analysed using dummy variables because the spacing of the toes was not consistent for each individual and was not a continuous variable [23]. The results of the simple footprint assessment board were set as explanatory variables and the navicular index, tibiocalcaneal angle, and calcaneal inclination angle, were set as objective variables for the analysis. With the medial side of the first toe as a reference, a dummy variable was created as the results of the simple footprint assessment board (1 if applicable, 0 otherwise). Then, a regression analysis was conducted with all dummy variables as explanatory variables to evaluate how well the navicular index could be explained or predicted from the scores of the simple footprint assessment board. In addition to this, a regression analysis was conducted with the scores of the simple footprint as a continuous variable. The ICC was calculated using SPSS version 12 software (SPSS Inc., Chicago, IL).

The number of cases were difficult to set by power analysis in this test due to the use of dummy variables, and a statistician was consulted prior to determining the number of cases. The number of cases that could be secured for each assessment board value for arch height (divided into 8 levels between the medial side of the first toe to the fourth toe) was set as over 32, which equated to approximately 4 cases each.

\section{Results}

The current study examined $35 \mathrm{ft}$ of 30 patients with a mean age of 44.7 years. The patient characteristics are shown in Table 1. This included two patients who had already been diagnosed with flatfoot from clinical findings.

In the navicular index, regression analysis with the scores of the simple footprint assessment board as a dummy variable showed that when a footprint assessment board score of 0.5 was set as the reference point, the regression coefficients generally decreased as the simple footprint assessment board score increased (Table 2). Although the coefficient factor for a score of 2.5 was greater than that of 2 , the rest of the results showed that the navicular index decreased as the scores of the simple footprint assessment board increased. As the scores of the simple footprint assessment board decreased by approaching the great toe, the navicular index was higher, which is indicative of a higher likelihood of flatfoot. In addition, regression analysis with the value of the simple footprint assessment board as a continuous variable showed that there was a significant correlation between the score of simple footprint assessment board and navicular index: $\mathrm{y}=-0.883 \mathrm{x}+6.505, p<0.001$.

Table 1 Patient characteristics

\begin{tabular}{ll}
\hline $\mathrm{n}$ & 35 (30 patients) \\
Mean age & 44.7 (14-85) \\
Sex & Male, 21; Female, 9 \\
Affected side & Right, 20; Left, 15 \\
Mean height (cm) & $163.8 \pm 9.5$ \\
Mean weight (kg) & $62.5 \pm 14.7$ \\
Mean BMl & $23.2 \pm 5.1$ \\
Reason for undergoing CT & Foot injury: 14 \\
& Foot pain: 5 \\
& Hallux valgus: 4 \\
& Lisfranc osteoarthritis: 4 \\
& Accessory navicular: 3 \\
& Flat foot: 2, \\
& Ankle sprain: 1, \\
& Plantar fasciitis: 1 \\
& Sesamoid bones: 1 \\
\hline
\end{tabular}


Table 2 Navicular index. Regression analysis with the value of the simple footprint assessment board as a dummy variable

\begin{tabular}{|c|c|c|c|c|c|c|c|c|}
\hline $\begin{array}{l}\text { Score of arch check } \\
\text { board }\end{array}$ & $\mathrm{n}$ & $\begin{array}{l}\text { Mean navicular } \\
\text { index }\end{array}$ & $\begin{array}{l}\text { Regression } \\
\text { factor }\end{array}$ & Standard error & t-value & $P$-value & $\begin{array}{l}\text { Coefficient of } \\
\text { determination }\end{array}$ & $\begin{array}{l}\text { Adjusted coefficient of } \\
\text { determination }\end{array}$ \\
\hline (Intercept) & & & 6.370 & 0.479 & 13.299 & 0.000 & 0.658 & 0.569 \\
\hline Score 0.5 (Reference) & 2 & 6.4 & & & & & & \\
\hline Score 1 & 5 & 6.0 & -0.382 & 0.567 & -0.674 & 0.506 & & \\
\hline Score 1.5 & 5 & 5.2 & -1.200 & 0.567 & -2.117 & 0.044 & & \\
\hline Score 2 & 9 & 4.4 & -1.974 & 0.530 & -3.729 & 0.001 & & \\
\hline Score 2.5 & 6 & 4.5 & -1.905 & 0.553 & -3.444 & 0.002 & & \\
\hline Score 3 & 6 & 3.9 & -2.465 & 0.553 & -4.457 & 0.000 & & \\
\hline Score 3.5 & 1 & 3.7 & -2.670 & 0.830 & -3.218 & 0.003 & & \\
\hline Score 4 & 1 & 3.0 & -3.370 & 0.830 & -4.062 & 0.000 & & \\
\hline Score of arch check board & \multicolumn{2}{|c|}{ Regression factor } & \multicolumn{2}{|c|}{ Standard error } & t-value & $P$-value & $\begin{array}{l}\text { Coefficient of } \\
\text { determination }\end{array}$ & $\begin{array}{l}\text { Adjusted coefficient of } \\
\text { determination }\end{array}$ \\
\hline (Intercept) & \multicolumn{2}{|c|}{6.505} & \multicolumn{2}{|l|}{0.277} & 23.470 & 0.000 & 0.602 & 0.590 \\
\hline Score & \multicolumn{2}{|c|}{-0.883} & 0.125 & & -7.060 & 0.000 & & \\
\hline
\end{tabular}

Score of arch check board (explanatory variables: $\mathrm{x}$ )

Navicular index (objective variables: y)

Regression analysis with the value of the simple footprint assessment board as a continuous variable

Score of arch check board (explanatory variables: $\mathrm{x}$ )

Navicular index (objective variables: y),

In the tibiocalcaneal angle, regression analysis with the scores of the simple footprint assessment board as a dummy variable showed that when a footprint assessment board score of 0.5 was set as the reference point, the regression coefficients generally decreased as the simple footprint assessment board score increased (Table 3). In addition, regression analysis with the value of the simple footprint assessment board as a continuous variable showed that there was a significant correlation between the score of simple footprint assessment board and navicular index: $\mathrm{y}=-4.200 \mathrm{x}+$ 24.064, $p<0.001$.

In the calcaneal inclination angle, regression analysis with the scores of the simple footprint assessment board as a dummy variable showed that when a footprint assessment board score of 0.5 was set as the reference point, the regression coefficients generally increased as the simple footprint assessment board score increased (Table 4). In addition, regression analysis with the value of the simple footprint assessment board as a continuous variable showed that there was a significant correlation between the score of simple footprint assessment board and navicular index: $\mathrm{y}=6.053 \mathrm{x}+12.069, p<0.001$.

The results of the age-stratified survey were the same as the overall results for all groups (Additional file 1).

ICC of the simple footprint assessment board based on the data of every foot in this study was 0.93 . The interobserver ICC of the navicular index, tibiocalcaneal angle, and calcaneal inclination angle were $0.99,0.92$, and 0.93 respectively. The intraobserver ICC of the navicular index, tibiocalcaneal angle, and calcaneal inclination angle were $0.89,0.94$, and 0.89 respectively.

\section{Discussion}

Our results clearly indicate that arch height which was evaluated by the simple footprint assessment board was correlated with the navicular index, tibiocalcaneal angle, and calcaneal inclination angle by CT. The same results were not only obtained for all ages simultaneously, but also for young, middle-aged, and older patients. This means that simple footprint assessment board can potentially be a substitute to CT for the diagnosis of flatfoot for all patients.

Various footprint-based analyses for foot arch assessment have been developed in previous studies. A previous report by Cavanagh and Rodgers measured and calculated the arch index as defined as the proportion of area for the middle third and total toeless footprint [24]. Other reports have described the use of Irwin's footprint index or similar modified approaches to determine the severity of flatfoot by calculating the area of the arch in a footprint $[12,25,26]$. Another common assessment is the use of Clarke's angle, which is calculated by the angle between 1) the medial tangential line joining the medial margin of the first metatarsal head/heel, and 2) the line joining the first metatarsal head and apex of the concavity in the medial longitudinal arch $[12,14$, 27, 28]. Forriol and Pascual described the use of Chippaux-Smirak index to determine foot arch development, which was calculated by the ratio of the maximum width of the metatarsals to the minimum width of the arch [12, 14, 28-31]. In addition, Staheli et al. developed an index for plantar arch as defined by the ratio of the midfoot- to hindfoot-width that is used as an indicator of foot arch development [12, 
Table 3 Tibiocalcaneal angle. Regression analysis with the value of the simple footprint assessment board as a dummy variable

\begin{tabular}{|c|c|c|c|c|c|c|c|c|}
\hline $\begin{array}{l}\text { Score of arch check } \\
\text { board }\end{array}$ & $n$ & $\begin{array}{l}\text { Mean navicular } \\
\text { index }\end{array}$ & $\begin{array}{l}\text { Regression } \\
\text { factor }\end{array}$ & $\begin{array}{l}\text { Standard } \\
\text { error }\end{array}$ & t-value & $P$-value & $\begin{array}{l}\text { Coefficient of } \\
\text { determination }\end{array}$ & $\begin{array}{l}\text { Adjusted coefficient } \\
\text { of determination }\end{array}$ \\
\hline (Intercept) & & & 26.000 & 1.232 & 21.107 & 0.000 & 0.876 & 0.838 \\
\hline Score 0.5 (Reference) & 2 & 6.4 & & & & & & \\
\hline Score 1 & 5 & 6.0 & -5.940 & 1.458 & -4.075 & 0.000 & & \\
\hline Score 1.5 & 5 & 5.2 & -10.440 & 1.458 & -7.163 & 0.000 & & \\
\hline Score 2 & 9 & 4.4 & -10.917 & 1.422 & -7.675 & 0.000 & & \\
\hline Score 2.5 & 6 & 4.5 & -12.520 & 1.458 & -8.590 & 0.000 & & \\
\hline Score 3 & 6 & 3.9 & -13.900 & 1.422 & -9.772 & 0.000 & & \\
\hline Score 3.5 & 1 & 3.7 & -16.300 & 2.134 & -7.640 & 0.000 & & \\
\hline Score 4 & 1 & 3.0 & -17.000 & 2.134 & -7.968 & 0.000 & & \\
\hline Score of arch check board & \multicolumn{2}{|c|}{ Regression factor } & Standard error & t-value & $P$-value & $\begin{array}{l}\text { Coefficient of } \\
\text { determination }\end{array}$ & \multicolumn{2}{|c|}{ Adjusted coefficient of determination } \\
\hline (Intercept) & \multicolumn{2}{|c|}{24.064} & 0.977 & 24.630 & 0.000 & 0.760 & \multicolumn{2}{|l|}{0.752} \\
\hline Score & \multicolumn{2}{|c|}{-4.200} & 0.438 & -9.590 & 0.000 & & & \\
\hline
\end{tabular}

Score of arch check board (explanatory variables: $\mathrm{x}$ )

Tibiocalcaneal angle (objective variables: $y$ )

Regression analysis with the value of the simple footprint assessment board as a continuous variable

Score of arch check board (explanatory variables: $\mathrm{x}$ )

Tibiocalcaneal angle (objective variables: y),

14, 31, 32]. Many researchers have recommended these procedures for foot arch assessment as a reliable screening method $[12,13]$. These procedures are simple and do not require any special equipment; however, the diagnostic methods require difficult and time-consuming tasks such as the measurement of area, angle, distance in addition to the calculation of their ratio [14].
Because flatfoot is a common disorder, a simpler and quicker diagnostic tool for flatfoot may be useful for a more diverse range of medical and healthcare professionals. The diagnosis of the disorder has to be dealt with across a spectrum of practitioners that is not limited to orthopaedic surgeons but also those who do not normally perform radiographic examinations, such as family practitioners, non-physicians, physical therapists,

Table 4 Calcaneal inclination angle. Regression analysis with the value of the simple footprint assessment board as a dummy variable

\begin{tabular}{|c|c|c|c|c|c|c|c|c|}
\hline $\begin{array}{l}\text { Score of arch check } \\
\text { board }\end{array}$ & $n$ & $\begin{array}{l}\text { Mean navicular } \\
\text { index }\end{array}$ & Regression factor & Standard error & t-value & $P$-value & $\begin{array}{l}\text { Coefficient of } \\
\text { determination }\end{array}$ & $\begin{array}{l}\text { Adjusted coefficient } \\
\text { of determination }\end{array}$ \\
\hline (Intercept) & & & 14.500 & 1.918 & 7.560 & 0.000 & 0.843 & 0.795 \\
\hline Score 0.5 (Reference) & 2 & 6.4 & & & & & & \\
\hline Score 1 & 5 & 6.0 & 3.580 & 2.269 & 1.578 & 0.128 & & \\
\hline Score 1.5 & 5 & 5.2 & 8.020 & 2.269 & 3.534 & 0.002 & & \\
\hline Score 2 & 9 & 4.4 & 8.667 & 2.215 & 3.913 & 0.001 & & \\
\hline Score 2.5 & 6 & 4.5 & 13.000 & 2.269 & 5.729 & 0.000 & & \\
\hline Score 3 & 6 & 3.9 & 15.167 & 2.215 & 6.849 & 0.000 & & \\
\hline Score 3.5 & 1 & 3.7 & 20.500 & 3.322 & 6.171 & 0.000 & & \\
\hline Score 4 & 1 & 3.0 & 22.500 & 3.322 & 6.773 & 0.000 & & \\
\hline Score of arch check board & \multicolumn{2}{|c|}{ Regression factor } & Standard error & & t-value & $P$-value & $\begin{array}{l}\text { Coefficient of } \\
\text { determination }\end{array}$ & $\begin{array}{l}\text { Adjusted coefficient of } \\
\text { determination }\end{array}$ \\
\hline (Intercept) & \multicolumn{2}{|c|}{12.069} & 1.165 & & 10.360 & 0.000 & 0.822 & 0.816 \\
\hline Score & \multicolumn{2}{|c|}{6.053} & 0.522 & & 11.590 & 0.000 & & \\
\hline
\end{tabular}

Score of arch check board (explanatory variables: $x$ )

Calcaneal inclination angle (objective variables: $y$ )

Regression analysis with the value of the simple footprint assessment board as a continuous variable

Score of arch check board (explanatory variables: $x$ )

Calcaneal inclination angle (objective variables: $y$ ), 
athletic trainers, orthotic prosthetists, and shoemakers. In this study, the effectiveness of a simple footprint assessment board that investigates which toe the cord passes through from the centre point of the heel to the most lateral point of the medial contour of the footprint with a thermochromic surface was evaluated. This board features the ability to accurately reproduce a footprint by the discoloration of its surface according to the patient's foot temperature, and the degree of flatfoot can be examined using the image of the footprint on the board by checking which toe the cord passes through from the centre point of the heel to the most lateral point of the medial contour of the footprint. Traditionally, a pedograph has been used for footprint analysis. This device consists of an inked rubber membrane of small grid lines that are imprinted on an underlying sheet of paper when a foot passes over it. In contrast, the simple footprint assessment board can be repeatedly used without ink or paper.

As a result of this study, the scores of the simple footprint assessment board was correlated with the navicular index, tibiocalcaneal angle, and calcaneal inclination angle measured by CT, not only when the result of the simple footprint assessment board was set as a noncontinuous variable but also when the result was set as a continuous variable. The intrarater reliability of the simple footprint assessment board, which was measured twice on every foot in this study, was high. Therefore, the data obtained from this simple footprint assessment board proved to be reproducible and reliable.

In the present study, one of the criteria which we used was the navicular index reported by Roth et al. [19]. They reported that values of the navicular index for flatfoot were in the interval from 4.75 to 31.20 (median 8.98 ) and for normal-arched foot 3.58 to 22.6 (median 5.48). Two of $35 \mathrm{ft}$ had already been diagnosed as flatfoot based on clinical findings. The navicular index values of these $2 \mathrm{ft}$ were 7.32 and 6.76 , and the scores in the simple footprint assessment board were 0.5 and 1 , respectively. On the other hand, it has been reported that if calcaneal inclination angle is less than 18 degrees, flat feet are more likely [33]. These results for known cases of flatfoot suggest that the diagnosis of flatfoot is highly likely if the cord of the simple footprint assessment board either passes through the great toe or over its medial side.

The height of the navicular bone was assessed using CT images instead of radiographic images in this study. The measurements of various angles on radiographs are always challenging due to superimposition of the bones. Furthermore, radiographs lack reproducibility and are associated with rotational and fan distortions [18]. In contrast, CT images have the advantage of multiplanar capabilities and higher resolutions. Since the interobserver and intraobserver ICC were sufficiently high, the evaluation of radiographic variables was reliable.

This study has limitations. Firstly, CT images were taken in the supine position and did not undergo imaging under load. Compared with non-weight-bearing images, weightbearing images better demonstrate the severity of osseous derangement in patients with flat foot [21]. The results of the present study can show the usefulness of the simple footprint assessment board to diagnose rigid flat foot which is a loss of medial arch in an unloaded condition. On the other hand, the validity of this board for the diagnosis of flexible flatfoot, which is loss of the inner arch in a loaded condition and more common in children, could not be examined because non weight-bearing CT images were applied to measure the navicular index. However, the results of the tibiocalcaneal angle and calcaneal inclination angle were well-correlated with both weight-bearing and nonweight-bearing conditions [21, 33]. Future research should be conducted with weight-bearing CT images for radiological evaluation to clarify the usefulness of simple tools like the simple footprint assessment board for diagnosis of flexible flatfoot. Secondly, all included patients suffered from foot pain, foot injury, or symptoms around the foot and underwent $\mathrm{CT}$ due to further examination for diagnosis. The disorders of the patients included in the study may influence the results. Nevertheless, the findings of this study suggest the possible clinical application of the simple footprint assessment board to detect flatfoot.

\section{Conclusions}

The findings of this study suggest that a simple footprint assessment board can be potentially useful to aid the detection of flatfoot for all patients without need for specialized training. Further studies with a larger sample size and greater variation of comparative radiological indices should be conducted to validate the simple footprint assessment board as a standard procedure for the diagnosis of flatfoot.

\section{Abbreviations}

$\mathrm{CT}$ : Computer tomography; ICC: Intraclass correlation coefficient

\section{Supplementary Information}

The online version contains supplementary material available at https://doi. org/10.1186/s12891-021-04154-3.

Additional file 1. Results of the age-stratified survey

\section{Acknowledgements}

Not applicable.

Authors' contributions

ST and NS conceived and designed the study, analysed and interpreted the patient data, and wrote the initial draft of the manuscript. YY, SA, and TN were major contributors in writing the manuscript. HK and $Y S$ aided in the interpretation of results. WM was in charge of overall direction and planning. All authors read and approved the final manuscript. 


\section{Funding}

This research received no specific grant from any funding agency in the public, commercial, or not-for-profit sectors.

\section{Availability of data and materials}

The datasets generated and/or analysed during the current study are available in the UMIN repository. UMIN000042719.

\section{Declarations}

\section{Ethics approval and consent to participate}

The study protocol was approved by the institutional review board of Teikyo University School of Medicine and all patients provided informed consent. All experiments were performed in accordance with the Declaration of Helsinki.

\section{Consent for publication}

Not applicable.

\section{Competing interests}

The authors declare that they have no competing interests.

\section{Author details}

${ }^{1}$ Department of Orthopaedic Surgery, Teikyo University School of Medicine Tokyo, Japan. ${ }^{2}$ Department of Orthopaedic Surgery, Shimazaki Hospital, Ibaraki, Japan. ${ }^{3}$ Department of Information Engineering, Tokyo University of Science, Tokyo, Japan. ${ }^{4}$ Faculty of Medical Technology, Teikyo University Institute of Sports Science and Medicine, Tokyo, Japan.

\section{Received: 10 December 2020 Accepted: 5 March 2021}

Published online: 18 March 2021

\section{References}

1. Toullec E. Adult flatfoot. Orthop Traumatol Surg Res. 2015;101(1 Suppl):S117. https://doi.org/10.1016/j.otsr.2014.07.030.

2. Otsuka R, Yatsuya H, Miura Y, Murata C, Tamakoshi K, Oshiro K, Nishio N, Ishikawa M, Zhang HM, Shiozawa M, Kobayashi A, Ito M, Hori Y, Kondo T, Toyoshima $\mathrm{H}$. Association of flatfoot with pain, fatigue and obesity in Japanese over sixties. Nihon Koshu Eisei Zasshi. 2003;50(10):988-98 (in Japanese)

3. Pita-Fernandez S, Gonzalez-Martin C, Alonso-Tajes F, et al. Flat foot in a random population and its impact on quality of life and functionality. J Clin Diagn Res. 2017;11(4):Lc22-Ic27.

4. Ross MH, Smith MD, Vicenzino B. Reported selection criteria for adult acquired flatfoot deformity and posterior tibial tendon dysfunction: are they one and the same? A systematic review. PLoS One. 2017 Dec;12(12): e0187201. https://doi.org/10.1371/journal.pone.0187201.

5. Yao K, Yang TX, Yew WP. Posterior tibialis tendon dysfunction: overview of evaluation and management. Orthopedics. 2015;38(6):385-91. https://doi. org/10.3928/01477447-20150603-06.

6. lijima H, Ohi H, Isho T, Aoyama T, Fukutani N, Kaneda E, Ohi K, Abe K, Kuroki $\mathrm{H}$, Matsuda S. Association of bilateral flat feet with knee pain and disability in patients with knee osteoarthritis: a cross-sectional study. J Orthop Res. 2017;35(11):2490-8. https://doi.org/10.1002/jor.23565

7. Ponce de León Samper MC, Herrera Ortiz G, Castellanos Mendoza C. Relationship between flexible flat foot and developmental hip dysplasia. Rev Esp Cir Ortop Traumatol. 2015;59(5):295-8. https://doi.org/10.1016/j.recot.201 5.02.005.

8. Abousayed MM, Alley MC, Shakked R, Rosenbaum AJ. Adult-acquired flatfoot deformity: etiology, diagnosis, and management. JBJS Rev. 2017;5(8): e7. https://doi.org/10.2106/JBJS.RWW.16.00116.

9. Pfeiffer M, Kotz R, Ledl T, Hauser G, Sluga M. Prevalence of flat foot in preschool-aged children. Pediatrics. 2006;118(2):634-9. https://doi.org/10.1 542/peds.2005-2126.

10. Villarroya MA, Esquivel JM, Tomás C, Moreno LA, Buenafé A, Bueno G. Assessment of the medial longitudinal arch in children and adolescents with obesity: footprints and radiographic study. Eur J Pediatr. 2009;168(5): 559-67. https://doi.org/10.1007/s00431-008-0789-8.

11. Banwell HA, Paris ME, Mackintosh S, Williams CM. Paediatric flexible flat foot: how are we measuring it and are we getting it right? A systematic review. J Foot Ankle Res. 2018;11(1):21. https://doi.org/10.1186/s13047-018-0264-3.
12. Chen KC, Yeh CJ, Kuo JF, Hsieh CL, Yang SF, Wang CH. Footprint analysis of flatfoot in preschool-aged children. Eur J Pediatr. 2011;170(5):611-7. https://doi.org/10.1007/s00431-010-1330-4.

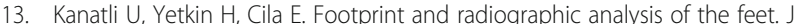
Pediatr Orthop. 2001;21(2):225-8. https://doi.org/10.1097/01241398-200103 000-00018.

14. Pita-Fernández S, González-Martín C, Seoane-Pillado T, et al. Validity of footprint analysis to determine flatfoot using clinical diagnosis as the gold standard in a random sample aged 40 years and older. J Epidemiol. 2015; 25(2):148-54. https://doi.org/10.2188/jea.JE20140082.

15. Langley B, Cramp M, Morrison SC. Clinical measures of static foot posture do not agree. J Foot Ankle Res. 2016;9(1):45. https://doi.org/10.1186/s13047016-0180-3.

16. Chen $\mathrm{CH}$, Huang $\mathrm{MH}$, Chen TW, Weng MC, Lee $\mathrm{CL}$, Wang GJ. The correlation between selected measurements from footprint and radiograph of flatfoot. Arch Phys Med Rehabil. 2006;87(2):235-40. https://doi.org/10.101 6/j.apmr.2005.10.014.

17. Lin YC, Mhuircheartaigh JN, Lamb J, Kung JW, Yablon CM, Wu JS. Imaging of adult flatfoot: correlation of radiographic measurements with MRI. AJR Am J Roentgenol. 2015;204(2):354-9. https://doi.org/10.2214/AJR.14.12645.

18. Pilania $K$, Jankharia $B$, Monoot $P$. Role of the weight-bearing cone-beam CT in evaluation of flatfoot deformity. Indian J Radiol Imaging. 2019;29(4):36471. https://doi.org/10.4103/ijri.IJRI_288_19.

19. Roth S, Roth A, Jotanovic Z, Madarevic T. Navicular index for differentiation of flatfoot from normal foot. Int Orthop. 2013;37(6):1107-12. https://doi. org/10.1007/s00264-013-1885-6.

20. Lee S, Oliveira I, Pressney I, Welck M, Saifuddin A. The horizontal calcaneofibular ligament: a sign of hindfoot valgus on ankle MRI. Skelet Radiol. 2019;49(5):739-46.

21. de Cesar NC, Schon LC, Thawait GK, et al. Flexible adult acquired flatfoot deformity: comparison between weight-bearing and non-weight-bearing measurements using cone-beam computed tomography. J Bone Joint Surg Am. 2017:99(18):e98.

22. Haldar A, Bernasconi A, Junaid SE, Lee KHB, Welck M, Saifuddin A. 3D imaging for hindfoot alignment assessment: a comparative study between non-weight-bearing MRI and weight-bearing CT. Skelet Radiol. 2021;50(1): 179-88. https://doi.org/10.1007/s00256-020-03532-7.

23. McCrohan KF, Harvey JW. A comparison of dummy variable versus traditional multiple discriminant function analysis. Health Mark Q. 1989;6(4): 147-57. https://doi.org/10.1300/J026v06n04_11.

24. Cavanagh PR, Rodgers MM. The arch index: a useful measure from footprints. J Biomech. 1987;20(5):547-51. https://doi.org/10.1016/0021-92 90(87)90255-7.

25. Irwin LW. A study of the tendency of school children to develop flatfootedness. Res Q. 1937:8:46-53.

26. Pandey S, Pal CP, Kumar D, Singh P. Flatfoot in Indian population. J Orthop Surg. 2013;21(1):32-6. https://doi.org/10.1177/230949901302100110.

27. Pauk J, Ihnatouski M, Najafi B. Assessing plantar pressure distribution in children with flatfoot arch: application of the Clarke angle. J Am Podiatr Med Assoc. 2014;104(6):622-32. https://doi.org/10.7547/8750-7315-104.6.622.

28. Forriol F, Pascual J. Footprint analysis between three and seventeen years of age. Foot Ankle. 1990;11(2):101-4. https://doi.org/10.1177/107110079001100208.

29. Gonzalez-Martin C, Pita-Fernandez S, Seoane-Pillado T, Lopez-Calviño B, Pertega-Diaz S, Gil-Guillen V. Variability between Clarke's angle and ChippauxSmirak index for the diagnosis of flat feet. Colomb Med. 2017:48(1):25-31.

30. Onodera AN, Sacco IC, Morioka EH, et al. What is the best method for child longitudinal plantar arch assessment and when does arch maturation occur? Foot. 2008;18(3):142-9.

31. El O, Akcali $O$, Kosay $C$, et al. Flexible flatfoot and related factors in primary school children: a report of a screening study. Rheumatol Int. 2006;26(11): 1050-3. https://doi.org/10.1007/s00296-006-0128-1.

32. Staheli LT, Chew DE, Corbett M. The longitudinal arch. A survey of eight hundred and eighty-two feet in normal children and adults. J Bone Joint Surg Am. 1987;69(3):426-8.

33. Agoada D, Kramer PA. Radiographic measurements of the talus and calcaneus in the adult pes planus foot type. Am J Phys Anthropol. 2020; 171(4):613-27. https://doi.org/10.1002/ajpa.23994.

\section{Publisher's Note}

Springer Nature remains neutral with regard to jurisdictional claims in published maps and institutional affiliations. 